\title{
O estudo de Claudio Galeno como fonte de conhecimento da anatomia humana
}

\author{
Camille Bertha Stülp \\ Graduanda em Fonoaudiologia - UFSC \\ camille.stulp@gmail.com
}

\author{
Samira Schultz Mansur \\ Profa. Dra. Depto. Ciências Morfológicas UFSC \\ samira.mansur@ufsc.br
}

\footnotetext{
Como citar este artigo: Stülp, Camille Bertha; Mansur, Samira Schultz. "O estudo de Claudio Galeno como fonte de conhecimento da anatomia humana”. Khronos, Revista de História da Ciência, no 7, pp. 153-169. 2019. Disponível em $<$ http://revistas.usp.br/khronos $>$. Acesso em dd/mm/aaaa.
}

Resumo: A anatomia humana foi estudada formalmente pela primeira vez no Egito e logo se caracterizou por observações diretas e princípios da filosofia, já que a sua compreensão se dá à luz da evolução dos seres. Esta pesquisa objetivou compreender o estudo de Galeno como fonte de conhecimento da anatomia humana, além de descrever a sua biografia com ênfase em suas contribuições à anatomia humana e relacionar seus achados e exegese anatômica frente às descobertas de outros filósofos. Concluiu-se que a compreensão da anatomia exige o resgate social e cultural da Grécia, onde os primeiros filósofos viveram, e que a ideologia de Galeno teve como cerne a sua criatividade e a sua originalidade.

Palavras-chave: Galeno, anatomia humana, história, filósofos.

\section{The Study of Claudio Galen as a Source of Knowledge of Human Anatomy}

Abstract: Human anatomy was formally study for the first time at Egypt and was soon characterized by direct observations and principles of philosophy, since that its comprehension comes in the light of evolution being. This research aimed to understand the study of Galen as a source of human anatomy knowledge, besides to describe his biography with emphasis on his contributions to human anatomy and to relate his findings and anatomical exegesis in the face of discoveries of others philosophers. It was concluded that anatomy's understanding requires the social and cultural rescue of Greece, where the first philosophers lived, and that Galen's ideology was based on his creativity and originality.

Keywords: Galen, human anatomy, history, philosophers. 


\section{Introdução}

Desde os primórdios da humanidade houve tentativas diversas de se entender o corpo humano e sua relação com a mente e a natureza. Entre as civilizações que assim comportaramse estão a do Egito, Mesopotâmia, Índia, China, as quais estavam familiarizadas com órgãos do corpo humano, tais como cérebro, coração, fígado, pulmões, estômago, intestinos, rins ${ }^{1}$. Todavia, foi a Grécia Antiga que proporcionou avanço ao conhecimento e deixou legados fundamentais ao pensar ocidental ${ }^{2}$, ensejando possibilidades à evolução humana em todas as ciências. Em se tratando da biologia, o primeiro conhecimento adquirido foi o da anatomia, devido ao corte dos animais para a alimentação e dos mortos para embalsamento ${ }^{3}$.

A Antiguidade Clássica, que compreende marcos culturais gregos determinantes a nossa civilização, de alguma forma recebeu ensinamentos de povos mais antigos, os quais impulsionaram descobertas e o aperfeiçoamento de ideias anteriores. Nos poemas épicos atribuídos a Homero - Ilíada e Odisseia - surgem considerações no que tange a geografia, astronomia, medicina, pintura, arquitetura, arte militar, anatomia, que, no entanto, ainda não eram tratadas como ciências de fato ${ }^{4}$. Ademais, o pensamento grego, bem como a estrutura social e cultural da Grécia, puderam ser acessados por meio dessas obras, compostas na segunda metade do século VIII a.C. e com gêneros literários distintos 5 .

Em Ilíada, uma epopeia - diferente do romance de Odisseia - citam-se momentos ao longo das batalhas entre gregos e troianos, ora acompanhados por morte, ora por ferimentos em variados segmentos do corpo, que ofereceram noções de localização dos órgãos e, consequentemente, a formulação de estratégias para atingir fisicamente o inimigo de maneira eficaz. Obviamente que a anatomia entendida nessa época limitava-se a confrontos com o inimigo e às melhores formas para eliminar o adversário, o que incluía saber a localização de órgãos vitais, os quais, se atingidos, causariam a morte. Depreende-se que havia um entendimento anatômico, mesmo que restrito e com uma única finalidade, à qual não se acrescentava o detalhamento morfológico do corpo e a compreensão de seu funcionamento.

\footnotetext{
${ }^{1}$ ROSA, Carlos Augusto de Proença. História da Ciência: Da Antiguidade ao Renascimento Cientifico. 2. ed. vol. 1. Brasília: Fundação Alexandre de Gusmão, 2010.

${ }^{2}$ CASTRO, Fabiano S; LANDEIRA-FERNANDEZ, J. Alma, Corpo e a Antiga Civilização Grega: As Primeiras Observações do Funcionamento Cerebral e das Atividades Mentais. Psicologia: Reflexão e Crítica, v.24, n.4, p.798-809, 2010.

${ }^{3}$ ROSA, 2010, op. cit.

${ }^{4}$ MALTA, André. Morte e Vida de Homero: Três visões do poeta grego publicadas no século XVIII. Revista USP São Paulo, n. 94, p.166-175. 2012.

${ }^{5}$ PORTO, Marco A. T., MOREIRA, Marcos Fernandes da Silva, SIMÃO, Marne Cristine de Figueiredo. Anatomia e Fisiologia na Idade Trágica dos Gregos. Revista de Humanidades, v.1, n. 1, p. 1- 17, 2000 ; CASTRO; LANDEIRA-FERNANDES, 2010, op. cit.
} 
A anatomia humana foi estudada formalmente pela primeira vez no Egito, em Alexandria - cidade fundada em 331 a.C. por Alexandre Magno, no oeste do delta do Nilo, e obra do arquiteto Denócares de $\operatorname{Rodes}^{6}$, logo se caracterizando por observações diretas e princípios da filosofia. As escolas de medicina de Alexandria impulsionaram o estudo da anatomia, por Herófilo, e fisiologia, por Erasístrato, os quais, entre os séculos III e IV a.C., realizaram expressivos avanços nestas áreas, especialmente pela prática da dissecação, a qual não era proibida no Egito ${ }^{7}$, mas foi abandonada em muitos locais até o século XVI ${ }^{8}$. Este fato também ocorreu devido a diversidade cultural nestas escolas, amealhando ideias e tradições macedônicas, egípcias, persas, judias, sírias, gregas, entre outras ${ }^{9}$, viabilizando o progresso da ciência anatômica.

Durante o governo do general Ptolomeu, que esteve no controle da cidade a partir de 323 a.C., a dissecação foi instituída em cursos gratuitos, bem como foram salvaguardados os textos sobre o tema, entre os quais os tratados hipocráticos ${ }^{10}$. Incêndios sistemáticos por causas incertas - invasões dos romanos, terremotos, negligências -, que atingiram a biblioteca da escola de Alexandria, destruíram diversos desses tratados ${ }^{11}$. Vale citar que a escola de Alexandria foi construída sob fundamental contribuição de Demétrio de Falero (350-360 a.C. a 285 a.C.), grego formado pela escola peripatética e que foi o elo para criar um projeto de ramificação do Liceu em Alexandria ${ }^{12}$.

Alexandria foi o centro comercial e cultural mais importante da antiguidade e onde estudaram diversos pensadores, entre eles anatomistas e filósofos, tais como Hipócrates, Herófilo, Erasístrato e o médico Claudio Galeno ${ }^{13}$. Segundo Galeno, os ptolomeus dedicavam-se a incrementar suas bibliotecas, por exemplo, era norma legal a doação de uma obra àquele que visitasse Alexandria ${ }^{14}$.

A partir deste contexto cultural, é na Grécia Antiga que a filosofia tem origem, cujo objeto propulsor de estudo foi o cosmos, por meio do qual se buscavam explicações naturais acerca do mundo ${ }^{15}$. Neste viés, em aproximadamente 585 a.C., o filósofo Tales de Mileto elencou a água como elemento primordial para o processo de observação ampla da natureza e posterior identificação racional de fenômenos, aos quais se incluía o homem e o entendimento do corpo

${ }^{6}$ BAEZ, Fernando. História universal da destruição dos livros: das tábuas sumérias à guerra do Iraque.

Tradução Léo Schlafman. Ediouro, 2004.

${ }^{7}$ ROSA, 2010, op. cit.

8 PEARCE, JMS. The neurology of erasistratus. Journal of Neurological Disorders, v.1, n.1, p. 1 - 3, 2013.

9 MARTÍNEZ, F.; DECUADRO-SÁENZ, G. Cláudio Galeno y los ventrículos cerebra-les. Parte I, los antecendentes. Neurocirurgia, v. 19, p.58 - 65, 2008.

${ }^{10}$ BAEZ, 2004, op. cit.

${ }^{11}$ BAEZ, 2004, op. cit.; MARTÍNEZ, DECUADRO-SAÉZ, 2008, op. cit.; ROSA, 2010, op. cit.

12 BAEZ, 2004, op. cit.

13 MARTÍNEZ, DECUADRO-SAÉZ, 2008, op. cit.

14 BAEZ, 2004, op. cit.

15 PORTO, MOREIRA, SIMÃO, 2000, op. cit.; CASTRO, LANDEIRA-FERNANDEZ, 2011, op. cit. 
e da mente ${ }^{16}$. Isto, porém, sem olvidar do conhecimento advindo dos filósofos pré-socráticos, cujas considerações sobre enfermidades, saúde e funcionamento do organismo humano foram usadas por médicos do século $\mathrm{V}$ a.C. ${ }^{17}$.

Galeno foi relevante intérprete de Hipócrates (460-377 a.C) e conciliou as ideias hipocráticas sobre o funcionamento do organismo saudável junto à filosofia de outros pensadores, tais como Platão (428-348 a.C) e Aristóteles (384-322 a.C) ${ }^{18}$. Seu conhecimento trouxe notável clareza sobre a morfologia e o funcionamento do organismo, assim como seus tratados foram essenciais para a história e a evolução da área da saúde ${ }^{19}$, concomitante ao estabelecimento da anatomia como vanguarda da ciência médica, fato que, com a familiaridade decorrente das dissecações, impeliu os investigadores a repensarem o corpo e seus distúrbios a partir da própria natureza da doença ${ }^{20}$. Nesse sentido, esta pesquisa objetivou compreender o estudo de Claudio Galeno como fonte de conhecimento da anatomia humana, bem como descrever sobre a sua biografia com ênfase em suas contribuições a esta ciência e relacionar seus achados e sua exegese anatômica frente às descobertas de outros filósofos.

\section{Biografia de Galeno e suas Contribuições à Anatomia Humana}

Claudio Galeno nasceu em 129 em Pérgamo, na Ásia Menor - atualmente Bergama, na Turquia. Seu pai, Nikon, um famoso arquiteto, após ser visitado em sonho pelo deus da medicina, Esculápio, orientou o filho para a área médica ${ }^{21}$. Sua morte ocorreu possivelmente na mesma cidade, entre $210^{22} \mathrm{e} 216^{23}$.

Galeno iniciou seus estudos cedo, em Pérgamo, os quais incluíram a matemática, a geometria e a filosofia e, aproximadamente com 16 anos, iniciou seus estudos de medicina, tendo escrito seu primeiro tratado em 151 ou 152 (com 21 ou 22 anos), o qual foi constituído por três livros sobre o movimento dos pulmões e do tórax ${ }^{24}$. Logo em seguida, de 152 a 157, foi estudar em outros centros culturais importantes como Esmirna, Corinto e Alexandria, expandindo seu

${ }^{16}$ CASTRO, LANDEIRA-FERNANDEZ, 2011, op. cit.

17 Idem

18 PORTER, Roy. Das tripas coração: uma breve história da medicina. Rio de Janeiro: Record, 2004.

19 ROSA, 2010, op. cit.; ALDERSEY-WILLIAMS, Hugh. Anatomias: Uma história cultural do corpo humano. Tradução de Waldéa Barcellos. 1 ed. Rio de Janeiro: Record, 2016.

20 PORTER, 2004, op. cit.

${ }^{21}$ PORTER, 2004, op. cit.; REBOLLO, Regina Andrés. O legado hipocrático e sua fortuna no período greco-romano: de Cós a Galeno. SCIENTIA Studia, São Paulo, v. 4, n. 1, p. 45 - 82, 2006; TALAMONI, Ana Carolina Biscalquini. Breve histórico da Anatomia: Anatomia, ensino e entretenimento. In: TALA-

MONI, Ana Carolina Biscalquini. Os nervos e os ossos do ofício: uma análise etnológica da aula de Anatomia [online]. São Paulo: Editora UNESP, p.23-37, 2014.

22 REBOLLO, 2006, op. cit.

23 PORTER, 2004, op. cit.

${ }^{24}$ REBOLLO, 2006, op. cit. 
conhecimento e escrevendo tratados de fisiologia e anatomia ${ }^{25}$. A anatomia foi aprimorada na escola de Alexandria, onde Galeno teve como professor Rúfus de Éfeso (110 a 180) e seu aprendizado foi guiado pelos ensinamentos de Herófilo (335 a 280 a.C.), além de ter sido o local onde obteve a sua base cultural para que colocasse suas teorias anatômicas em prática, diagnosticando e classificando doenças a partir de sinais e sintomas ${ }^{26}$.

Foi médico de gladiadores em Pérgamo (158-161) e, quando chegou em Roma, seus talentos anatômicos logo disseminaram seus valores, fazendo-o atuar também como médico do imperador Marco Aurélio (161-163) e de seu filho Comodo (169-175)27. Em 176 atingiu o auge de sua fama permanecendo na medicina da corte imperial até 192, quando um incêndio em Roma destruiu significativa parte de seus manuscritos, fazendo-o, em função de sua personalidade, dedicar-se a rescrever alguns, o que resultou na criação de seus mais importantes $\operatorname{tratados}^{28}$.

É importante relatar, conforme cita Baez (2004), a respeito da biblioteca de Pérgamo, a qual foi tão magnífica quanto a biblioteca de Alexandria, assim adjetivada por Vitrúvio. Fundada pelo rei Eumênio no século II a.C., a fim de rivalizar com os monarcas de Alexandria, reuniu cerca de 200 a 300 mil pergaminhos, material mais duradouro, usado devido a dificuldade de se obter papiro, já que Ptolomeu recusou-se a exportar o mesmo aos bibliotecários de Pérgamo na tentativa de obstaculizar seus trabalhos. Este fato levou a invenção dos livros de couro de carneiro em Pérgamo, que poderiam ter imortalizado vários ensinamentos, salvo se as bibliotecas não fossem destruídas. Galeno encontrou algumas falsificações nesta biblioteca, provavelmente pela pressa que se teve em organizar e montar o acervo, o que acarretou incongruências filológicas provenientes da extração de escritos que os bibliotecários avaliavam inconvenientes ou da omissão de alguns livros.

A personalidade de Galeno, refletida em seu comportamento, caracterizava-se por elevados princípios morais, autoconfiança, espírito combatente e indignado, mente enérgica e inquisitiva, aliados a vasto aprendizado, lógica impecável e retórica persuasiva ${ }^{29}$. Estes atributos, junto ao seu profundo conhecimento prático - inclusive com experimentações em si mesmo como se queimar em vários lugares da sua pele para identificar o melhor remédio para queimaduras - e à expansão de suas obras, garantiram sua autoridade por cerca de 15 séculos $^{30}$. Igualmente, era visto como egoísta e sua escrita autobiográfica e arrogante, pois fazia duras críticas e

${ }^{25}$ REBOLLO, 2006, op. cit.; STANDRING, Susan. A brief history of topographical anatomy. Journal Of Anatomy, v. 229, n. 1, p.32-62, 2016.

${ }^{26}$ MARTÍNEZ, DECUADRO-SAÉZ, 2008, op. cit.; MATTERN, Susan. The art of medicine Galen and his patients. The lancet, v. 378, p. $478-479,2011$.

27 PORTER, 2004, op. cit.; REBOLLO, 2006, op. cit.; MATTERN, 2011, op. cit.

${ }^{28}$ REBOLLO, 2006, op. cit.

29 PASIPOULARIDES, Ares. Galen, the father of systematic medicine. An essay on the evolution of modern medicine and cardiology. International Journal of Cardiology, v. 172, n. 1, p. 47 - 58, 2014.

${ }^{30}$ ROSA, 2010 op. cit; PASIPOULARIDES, 2014, op. cit. 
ridicularizava opiniões e métodos contrários ao dele ${ }^{31}$. Engajado em manifestações púbicas e debates, interessava-se por todos os ramos do conhecimento com habilidade e entusiasmo e, ao sustentar suas conclusões usando sua capacidade lógica e retórica, despertava animosidade entre alguns colegas ${ }^{32}$.

Para Galeno, o médico deveria dominar a lógica (arte de pensar), a física (ciência da natureza), a ética (norma de conduta), a filosofia - situada no âmago das ciências -, e a confiança do paciente, fato imprescindível para a cura, e não ser um simples prático de doenças baseado no empirismo ${ }^{33}$. Ele criticou os médicos que dispensavam quaisquer métodos antes de remediarem seus pacientes e ratificava o ensinamento hipocrático de que se deve ajudar o paciente e nunca lhe causar danos ${ }^{34}$. Entre as doenças descritas por Galeno estão a malária, a peste e a tuberculose ${ }^{35}$.

Ele não se preocupou somente com estados anormais de funcionamento do corpo, mas em desenvolver teorias sobre o organismo saudável, os quais são adjacentes à filosofia e fundamentadas nos pensamentos de Aristóteles e de Platão, em harmonia com Hipócrates, quem ele considerava de alta sapiência médica ${ }^{36}$. Para Galeno, muitas das complicações do organismo eram unicamente por motivos emocionais, reconhecendo a importância das emoções para se manter a saúde ${ }^{37}$. Por exemplo, as principais causas das doenças residiam na ansiedade e no sentimento de raiva - podendo exacerbar a epilepsia ou resultar em insônia, febre, melancolia juntamente com o desequilíbrio na dieta, no temperamento, no estilo de vida e em fatores ambientais ${ }^{38}$.

Em seus manuscritos conhecidos como corpo galênico - clássico mundial traduzido em vários vernáculos -, Galeno sistematizou o conhecimento anatômico atestando a relevância que atribuiu à anatomia em seu contexto médico e filosófico ${ }^{39}$. Foi o autor com mais obras na Antiguidade, sendo que apenas cerca de 130 manuscritos foram preservados, entre aproximadamente 600 obras, com temas intitulados "Introdução a Medicina; Comentários sobre Hipócrates; Ana-

\footnotetext{
31 BESSER, Michael. Galen and the Origins of Experimental Neurosurgery. Austin Jour-nal of Surgery, v.1, n. 2, p. $1-5,2014$.

32 PASIPOULARIDES, 2014, op. cit.

33 PORTER, 2004, op. cit.

34 TOTELIN, Laurence M.V. And to end on a poetic note: Galen's authorial strategies in the pharmacological books. Studies In History And Philosophy Of Science Part A, v. 43, n. 2, p.307-315, 2012.

35 MATTERN, 2011, op. cit.

36 PASIPOULARIDES, 2014, op. cit.

${ }^{37}$ MATTERN, 2011, op. cit.

38 Idem

${ }^{39}$ BESSER, 2014, op cit.; PASIPOULARIDES, 2014, op. cit.
} 
tomia e Fisiologia; Diagnóstico, Etiologia e Higiene; Dieta, Farmacologia e Terapêutica; Composição de Medicamentos de acordo com os Tipos; Composição de Medicamentos de acordo com os Locais" 40 .

A completude do corpo galênico embasou estudos e descobertas posteriores ${ }^{41}$, permitindo que a morfologia grega do corpo humano atingisse o mais alto nível sistemático ${ }^{42}$. Thomas Linacre, fundador do humanismo na Inglaterra entre os séculos XV e XVI, citou que, depois de Hipócrates, Galeno foi o maior benfeitor da saúde humana ${ }^{43}$.

O estudo da anatomia, para Galeno, possuía objetivos relacionados à prática de quaisquer tipos de cirurgias, ao exame físico do paciente, ao diagnóstico - partindo de sinais e sintomas - bem como à patologia e fisiologia ${ }^{44}$. Ressalta-se que, a seu ver, a compreensão do processo fisiológico é corolário dos estudos anatômicos, uma vez que a forma, a situação e outros detalhes estruturais característicos de órgãos, como textura, densidade, composição, não podem ser separados de suas funções ${ }^{45}$.

Seus trabalhos em anatomia foram baseados em dissecações e vivissecções de animais e seus órgãos, tais como bovinos, macacos, ovelhas, porcos, cabras, coração de elefante, já que em humanos estavam proibidas na sua época ${ }^{46}$ e, igualmente, pelo conhecimento obtido a partir das investigações realizadas por Herófilo e Erasístrato, com a dissecação de corpos humanos ${ }^{47}$. O propósito destas práticas anatômicas era mapear o corpo humano na intenção de descobrir o seu interior e não apenas as partes visíveis para, depois, explicar a função dos órgãos e sistemas ${ }^{48}$.

Em virtude do fato de os estudos práticos de Galeno terem sido fundamentados em animais, ele supôs que os mesmos eram anatomicamente idênticos aos humanos, conduzindo-o a alguns erros. Estes incluíam a ideia de que o fígado tinha cinco lobos, o coração três ventrícu$\operatorname{los}^{49}$, a formação do sangue ocorrida no fígado, o suco pancreático assemelhava-se à saliva ${ }^{50} \mathrm{e}$ de que havia poros dentro das paredes cardíacas que permitiam a circulação do sangue entre ambos os lados do coração ${ }^{51}$.

40 ROSA, 2010, op. cit.; TOTELIN, 2012, op. cit.; PASIPOULARIDES, 2014, op. cit.

${ }^{41}$ REBOLLO, 2006, op. cit.; ROSA, 2010, op. cit. PASIPOULARIDES, 2014, op. cit.

42 SOUZA, Sandro Cilindro de. Períodos da Anatomia. Revista de Ciências Médicas e Biológicas, Salvador, v. 10, n.1, p.03-06, 2011.

43 PASIPOULARIDES, 2014, op. cit.

44 PORTER, 2004, op. cit.; PASIPOULARIDES, 2014, op. cit.

45 PASIPOULARIDES, 2014, op. cit.

46 PORTER, 2004, op. cit.; ROSA, 2010, op. cit.; STANDRING, 2016, op. cit.

${ }^{47}$ STANDRING, 2016, op. cit.

48 PORTER, 2004, op. cit.; PASIPOULARIDES, 2014, op. cit.

49 PORTER, 2004, op. cit.

${ }^{50}$ NAVARRO, Salvador. Breve história de la anatomía y fisiología de una recóndita y enigmática glándula llamada páncreas. Gastroenterol Hepatol., v. 37, n. 9, p. 527-534, 2014.

51 STANDRING, 2016, op. cit. 
Entretanto, ele tinha consciência de algumas diferenças anatômicas entre humanos e animais, como as existentes em determinados músculos ${ }^{52}$. Provavelmente, os músculos, além dos ossos e nervos, foram bastante compreendidos por ele devido a sua condição de médico da escola de gladiadores de Pérgamo ${ }^{53}$. Os seus erros foram percebidos posteriormente, porém, assim como as suas numerosas contribuições, tiveram elevada importância à evolução do entendimento do corpo humano ${ }^{54}$.

Nesse seguimento, Galeno organizou a distribuição topográfica dos ossos e desenvolveu a anatomia do esqueleto ${ }^{55}$. Identificou a existência de músculos agonistas e antagonistas, descrevendo também a anatomia de músculos tais como o platisma, o orbicular da boca, o orbicular da pálpebra, o poplíteo, os músculos interósseos e lumbricais da mão e do pé, os músculos extrínsecos e intrínsecos da laringe e da língua, bem como de anexos musculares ${ }^{56}$.

As demonstrações públicas de dissecações e de vivissecções de Galeno expondo seu amplo saber anatômico e espetacular habilidade fina proporcionou-lhe respeito e reconhecimento - mas também inimigos ${ }^{57}$. A investigação aprofundada do corpo humano por meio destas práticas atribuiu singularidade à medicina ocidental, uma vez que nesta minuciosidade desvendavam-se os segredos da saúde e da doença, todavia, acabavam por estimular, de certa forma, a visão de partes do corpo em detrimento do todo ${ }^{58}$.

Há de se apontar que Galeno disseminou da Grécia as ideias de Hipócrates e, por isso, teve participação significativa na perpetuação da medicina e do pensamento hipocrático ${ }^{59}$. Ocorre que, entre ambos, houve Platão, Aristóteles, Herófilo, Erasístrato, médicos alexandrinos e romanos, por conseguinte, pode-se considerar o sistema galênico uma síntese criativa e original dos elementos herdados ${ }^{60}$, absorvendo e aproximando do que mais Galeno acreditava ${ }^{61}$. Para ele era necessário conciliar os pensamentos antigos com as novas descobertas anatômicas e concepções filosóficas, por isso sua exegese era composta por duas principais partes: o texto de Hipócrates, seguido por seus próprios esclarecimentos e comentários ${ }^{62}$.

52 TALAMONI, Ana Carolina Biscalquini. Breve histórico da Anatomia: Anatomia, ensino e entretenimento. In: TALAMONI, Ana Carolina. Os nervos e os ossos do ofício: uma análise etnológica da aula de Anatomia [online]. São Paulo: Editora UNESP, p.23-37, 2014;

${ }^{53}$ ROSA, 2010, op. cit.; STANDRING, 2016, op. cit.

54 PORTER, 2004, op. cit.; MATTERN, 2011, op. cit.; PASIPOULARIDES, 2014, op. cit.

55 PORTER, 2004, op. cit.; BESSER, 2014, op. cit.

${ }^{56}$ BESSER, 2014, op cit.; PASIPOULARIDES, 2014, op. cit.

${ }^{57}$ PORTER, 2004, op. cit.

${ }^{58}$ Idem

59 ALDERSEY-WILLIAMS, 2016, op. cit.

${ }^{60}$ PORTER, 2004, op. cit.

${ }^{61}$ REBOLLO, 2006, op. cit.

62 REBOLLO, 2006, op. cit.; PASIPOULARIDES, 2014, op. cit. 
O corpo, para Galeno, era constituído por partes significativas como o cérebro, o coração e o fígado, as quais controlavam as cavidades da cabeça, do tórax e do abdome ${ }^{63}$. Desta forma, os sistemas nervoso (cérebro), arterial (coração) e venoso (fígado) estavam separados e cada um distribuía pelo corpo uma das três pneumas, respectivamente, os espíritos psíquico, vital e natural ${ }^{64}$. O sistema circulatório de Galeno contemplava a interferência de três órgãos (cérebro, coração e fígado) que injetavam no corpo os sopros animal ou psíquico, vital e natural, os quais fluíam por meio de canais dos sistemas nervoso, arterial e venoso, respectivamente.

Dessa forma, o sangue era produzido no fígado pelos alimentos ingeridos (e transformados no estômago) e se distribuía pelo corpo através do sistema venoso; por meio das artérias, o sangue alcançava o cérebro que, por sua vez, transformava-o em sopro psíquico (ou animal) a ser distribuído pelos nervos ${ }^{65}$. A circulação sanguínea funcionava de modo que as veias originavam-se do fígado e as artérias do coração; o sangue do fígado alcançava o ventrículo direito cardíaco, de onde se destinava aos pulmões (pela artéria pulmonar) ou cruzava o coração (por meio poros nos septos) até o ventrículo esquerdo, local em que se misturava com o ar, aqueciase e seguia à periferia ${ }^{66}$. Galeno descreveu minuciosamente a conexão venosa com o coração e a autonomia do batimento cardíaco e demonstrou que as artérias contêm sangue, não $\operatorname{ar}^{67}$, conhecimento acreditado por Alcmaeon (540 a.C.), de Crotona (sudeste da Itália), o qual dizia que as artérias continham pneuma ${ }^{68}$.

Os órgãos supracitados (cérebro, coração e fígado) eram unidos pelos humores - sangue, fleuma, bile negra e bile amarela - e um fluido mais rarefeito - o espírito - o qual explicava a existência da alma e demonstrava uma visão holística do corpo ${ }^{69}$. O corpo, entre saúde e doença, bem como a forma e a constituição corporal e o comportamento humano, estariam submetidos às quantidades destes humores, os quais teriam propósitos específicos. Segundo Por$\operatorname{ter}^{70}$ : o sangue seria fonte de vitalidade - deixava o corpo quente e úmido e pessoas dotadas de sangue teriam a pele rosada, temperamento otimista, seriam animadas, alegres, robustas e impulsivas; a bile amarela era o suco gástrico - deixava o corpo seco e quente e pessoas com mais bile amarela tendiam a ser magras, criminosas e irritadiças; a fleuma incluía todas as secreções incolores do corpo - deixava o corpo úmido e frio e aqueles com mais fleuma no corpo se caracterizavam por serem gordos, pálidos, preguiçosos, inertes e de temperamento frio; e a bile negra era responsável por escurecer outros fluidos - produzia a sensação de frio e secura e pessoas com

${ }^{63}$ ALDERSEY-WILLIAMS, 2016, op. cit.

${ }^{64}$ ROSA, 2010, op. cit. PASIPOULARIDES, 2014, op. cit.

${ }^{65}$ ROSA, 2010, op. cit.

66 PORTER, 2004, op. cit.; STANDRING, 2016, op. cit.

${ }^{67}$ ROSA, 2010, op. cit.; BESSER, 2014, op cit.

68 PANEGYRES, Konstantine P., PANEGYRES, Peter K. The Ancient Greek discov-ery of the nervous system: Alcmaeon, Praxagoras and Herophilus. Journal of Clinical Neuroscience, v.29, p. 21-24, 2016.

${ }^{69}$ ALDERSEY-WILLIAMS, 2016, op. cit.

70 PORTER, 2004, op. cit. 
bile negra teriam aparência amorenada, seriam sarcásticas, desconfiadas e propensas a ver o lado negro das coisas.

Galeno, em seus estudos experimentais e teóricos, dedicou-se imensamente a desvendar o cérebro, o qual defendia ser o centro da inteligência e do controle do corpo. Era, pois, encefalocentrista, assim como Alcmaeon, Praxágoras, Hipócrates, Herófilo, Erasístrato, Platão, entre outros ${ }^{71}$. O filósofo Alcmaeon foi quem primeiramente aproximou a medicina do encefalocentrismo, teoria baseada em Pitágoras, na qual o cérebro é a sede da mente, do espírito e da lógica $^{72}$, bem como da consciência, das sensações e do conhecimento ${ }^{73}$. Diante disto, Galeno diferenciava-se de Aristóteles e dos Estoicos, uma vez que estes acreditavam no cardiocentrismo, teoria na qual o coração era o órgão sede das retro citadas funções ${ }^{74}$.

Galeno aperfeiçoou o conceito de sistema nervoso central, introduzido pro Herófilo, e descobriu as meninges e o líquido cefalorraquidiano circulando nos ventrículos encefálicos ${ }^{75}$. Descreveu o sistema nervoso autônomo ${ }^{76}$. Propôs que a medula espinal é uma extensão do cérebro, descrevendo a sua anatomia e esclarecendo as consequências da lesão medular ${ }^{77}$. Ademais, descobriu que os nervos torácicos e frênicos inervam músculos responsáveis pela respiração ${ }^{78}$, a qual pode ser submetida a controle voluntário e involuntário ${ }^{79}$ e está intimamente ligada a fonação ${ }^{80}$. Em uma de suas demonstrações públicas de vivissecção de animais mostrou, em um porco, o suprimento nervoso para a laringe e a perda da voz quando pequenos nervos (os laríngeos recorrentes) são amarrados ${ }^{81}$.

Entendia, igualmente a Herófilo, que nervos são caminhos para a comunicação de movimentos e sensações entre o sistema nervoso central e a periferia (músculos e vísceras), sendo o cérebro a principal fonte de sensibilidade e motilidade para todas as partes do corpo ${ }^{82}$ Seus métodos experimentais nos trabalhos de vivissecção em cérebros de animais e suas observações

\footnotetext{
${ }^{71}$ CRIVELLATO, Enrico; RIBATTI, Domenico. A Portrait of Aristotle as an Anato-mist: historical Article. Clinical Anatomy, [s. 1.], v. 20, p. 477 - 485, 2007; PANE-GYRES, PANEGYRES, 2016, op. cit. 72 PANEGYRES, PANEGYRES, 2016, op. cit.; ZEMELKA, Adam M. Alcmaeon of Croton - Father of Neuroscience? Brain, Mind and Senses in the Alcmaeon's Study. Journal of Neurology and Neuroscience, v. 08, n. 03, p.1-5, 2017.

${ }^{73}$ CRIVELLATO, RIBATTI, 2006, op. cit.

74 ZEMELKA, 2017, op. cit.

75 PASIPOULARIDES, 2014, op. cit.

76 MARTINEZ, DECUANDRO-SÁENZ, 2008, op. cit.

77 BARBARA, Jean-gaël; CLARAC, François. Historical concepts on the relations be-tween nerves and muscles. Brain Research, [s.1.], v. 1409, p.3-22, 2011; PASIPOU-LARIDES, 2014, op. cit.; TALAMONI, 2014, op. cit.

78 BESSER, 2014, op cit.

79 BARBARA, CLARAC, 2011, op. cit.

80 BESSER, 2014, op cit.; STANDRING, 2016, op. cit.

81 Idem

82 BARBARA, CLARAC, 2011, op. cit. PASIPOULARIDES, 2014, op. cit.
} 
de pacientes com lesão cerebral formaram a base para os conceitos das situações dos lobos do cérebro, prenunciando a estimulação cerebral usada até hoje ${ }^{83}$.

Outras descobertas de Galeno incluíram o fato de os rins (não a bexiga, como se acreditava) produzirem urina ${ }^{84}$ e a descrição do fluxo urinário pelos ureteres até a bexiga ${ }^{85}$. Ademais, descreveu os ductos das glândulas submandibulares e linguais ${ }^{86}$ e identificou o pâncreas como uma glândula, cuja função era proteger os vasos sanguíneos que passam por trás dela ${ }^{87}$.

O ensino e os modelos propostos por Galeno acerca da anatomia e do funcionamento do organismo humano foram aceitos até o Renascimento, período no qual surgiram questionamentos a seus achados especialmente por parte de Vesálio e de Harvey ${ }^{88}$. Ocorre que muitos dos ensinamentos galênicos mantiveram-se mesmo após serem refutados, principalmente no que tange à perspectiva teleológica da função muscular baseada na forma e localização dos múscu$\operatorname{los}^{89}$.

Andreas Vesalius (1514 a 1564), autor do atlas de anatomia De Humani Corporis Fabrica, com descrições e ilustrações do esqueleto, músculos, sistema nervoso, vísceras e vasos sanguíneos, contrapôs vários ensinamentos de Galeno e censurou-o por fundamentar seus estudos no conhecimento de corpos de animais e não de seres humanos, entretanto, a anatomia pós-vesaliana ainda raciocinou predominantemente conforme Galeno ${ }^{90}$. Já William Harvey (1578 a 1657) apontou falhas de Galeno quanto ao funcionamento cardíaco, o que possibilitou a evolução no conhecimento da fisiologia do coração ${ }^{91}$. Um dos notáveis esclarecimentos de Harvey, embora tenha sido inicialmente rejeitado, foi quanto a separação definitiva dos sistemas nervoso e cardiovascular92. Vale citar que Herófilo já havia apontado a respeito desta individualização de siste$\operatorname{mas}^{93}$.

Exegese Anatômica de Galeno frente a Descobertas de outros Filósofos

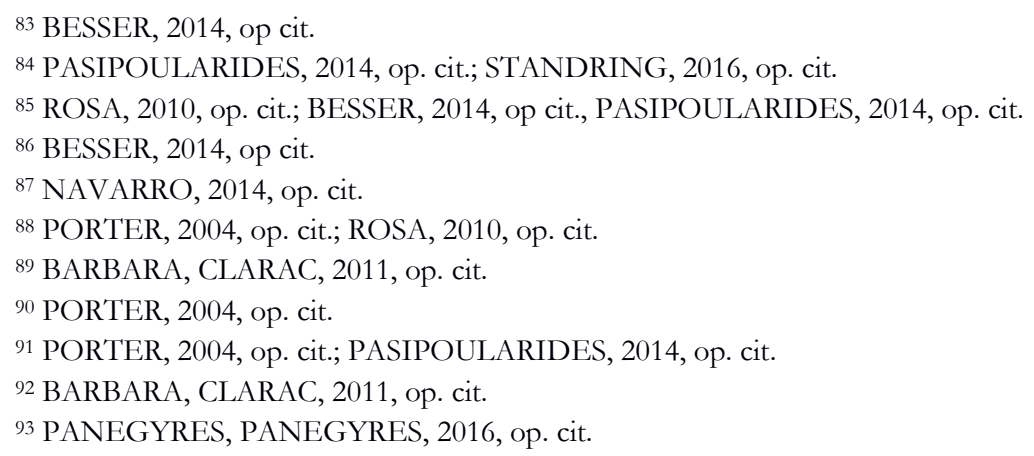


Galeno foi o primeiro compilador do conhecimento adquirido anteriormente a ele e dedicou-se especialmente a conciliar a filosofia natural de Hipócrates ${ }^{94}$, seguindo, em sua prática clínica, os princípios hipocráticos ao permitir a cura primeiramente pela ação da natureza, intervindo somente quando ela não se mostrasse eficaz ${ }^{95}$. Entretanto, mesclava esta compreensão às filosofias de Platão e de Aristóteles, o que se tornou público com o hipocratismo galênico ${ }^{96}$. Este durou até o século XV, quando médicos e filósofos, influenciados por humanistas, começaram a exigir obras livres de comentários e interpretações pessoais ${ }^{97}$.

Similarmente, nas obras conhecidas como corpus hippocraticum ou corpo hipocrático, estavam presentes os pensamentos do homem grego anteriores a Hipócrates, os denominados présocráticos (Sócrates, 470 a 379 a.C.), entre os quais Alcmaeon de Crotona. O corpo hipocrático, embora se refira a Hipócrates, é um conjunto de obras de vários autores reunidas e publicadas pelos copistas de Alexandria, totalizando 153 escritos, dispostos em 72 livros e 59 tratados que agrupam as bases do pensamento médico e filosófico de 420 a 350 a.C., os quais eram usados como um manual na orientação teórica da aprendizagem médica, esta que era voltada à oralidade ${ }^{98}$. Assim, a medicina grega se estabeleceu por volta do século V a.C. em virtude da nova perspectiva da escola liderada por Hipócrates ${ }^{99}$.

Importante relatar que os ensinamentos médicos eram tradicionalmente transmitidos de pai para filho ou discípulo até os períodos helenístico e romano e, a partir de então, uma nova tradição surgiu nas cidades de Alexandria, cujos representantes eram Herófilo e Erasístrato, e de Pérgamo, com Galeno ${ }^{100}$. Todavia, o conhecimento de Hipócrates continuou a influenciar o pensamento médico ocidental e suas obras foram primeiramente sistematizadas e glosadas por Herófilo, mas principalmente por Galeno ${ }^{101}$, o qual criticou alguns intérpretes de Hipócrates por terem tido excessiva liberdade com o texto, eliminando lições antigas em substituição a suas próprias ideias ${ }^{102}$. Vale citar que após a partida de Hipócrates da escola de Cós para Tessália (norte da Grécia), em cerca de 419 e 416 a.C., seu genro Políbio ficou à frente da mesma, zelando por manter a transmissão de conhecimento de forma tradicional ${ }^{103}$.

Hipócrates de Cós (459-377 a.C.), considerado o "pai da medicina", era oriundo de família médica e formou-se na escola de Cós, na qual o ensino entendia a doença como a desarmonia entre o corpo e a natureza e onde o aprendizado era técnico, baseado na arte manual,

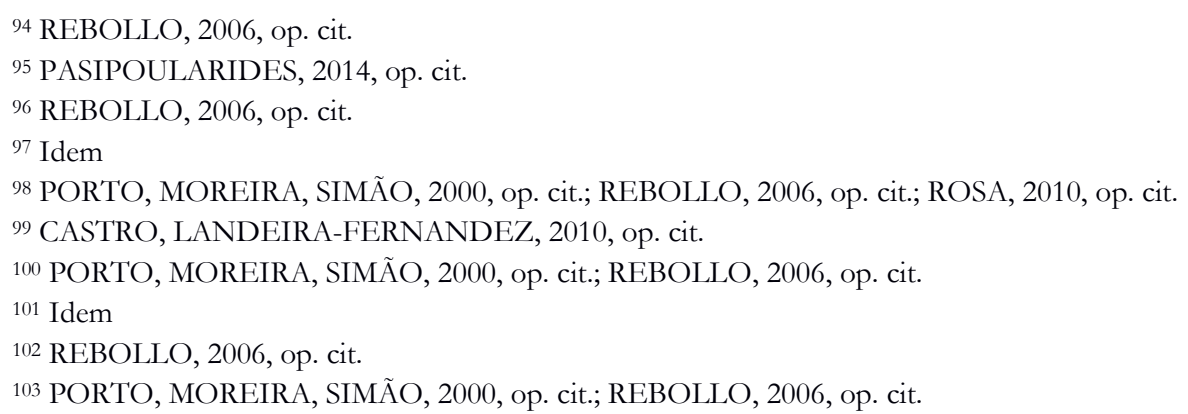


com formação teórica, prática e itinerante - conforme a escola peripatética -, com noções de filosofia natural e retórica, semiologia, farmacologia, cirurgia e rudimentos de anatomia ${ }^{104}$, já que a dissecação, que permitia o aperfeiçoamento anatômico, não fez parte da medicina hipocrática. A desmitificação da doença, a procura de suas causas naturais, o registro cuidadoso, consciente e objetivo da evolução dos sintomas da enfermidade e do respectivo tratamento, foram as principais e decisivas contribuições de Hipócrates e de seus discípulos da escola de Cós à medicina ${ }^{105}$.

Os trabalhos de Hipócrates marcaram a busca pelas causas das doenças com fundamentações naturais, lógicas e racionais, a partir de teorias advindas da natureza e esquecendo o pensamento de que havia uma origem divina das moléstias ${ }^{106}$. Suas obras foram usadas como manuais de ensino em uma época em que a moralidade passou a ser substituída por escritos ${ }^{107}$.

Segundo os conceitos hipocráticos, à atuação médica importava o conhecimento da natureza do corpo e de suas alterações nas doenças, a fim de reconhecê-las, identificá-las e tratálas, bem como a formação moral e intelectual do médico, a sua conduta no atendimento clínico e seu domínio no uso de instrumentos e técnicas de intervenção ${ }^{108}$. Assim, os três princípios gerais que guiavam o médico hipocrático - o qual atuava a partir de sua experiência sensorial para raciocinar e intervir manualmente, dedicando-se a sua arte sem almejar fama ou fortuna, tampouco curas milagrosas -, eram: ser útil ao doente (apresentavam-se como amigos fieis, consolando os pacientes angustiados), abster-se dos casos incuráveis (comprometiam-se a não prejudicar os pacientes reconhecendo as limitações frente àquilo que é necessário na natureza) e atacar terapeuticamente as causas da doença ${ }^{109}$.

Em todas as civilizações antigas, o marco da investigação funcional do organismo era a análise de elementos do mundo exterior, como o ar e a comida, e de líquidos corporais, como o sangue, estabelecendo relação entre eles ${ }^{110}$. Neste sentido, para a filosofia hipocrática o corpo era constituído por quatro humores, sangue, fleuma, bile amarela e bile negra, e a saúde estaria associada ao equilíbrio entre eles, contrariamente ao desequilíbrio manifestado por alguma doença $\mathrm{a}^{111}$. Este entendimento foi similar ao disseminado e aperfeiçoado por Galeno, o qual adicionou à teoria dos humores de Hipócrates, a análise do temperamento e comportamento humanos.

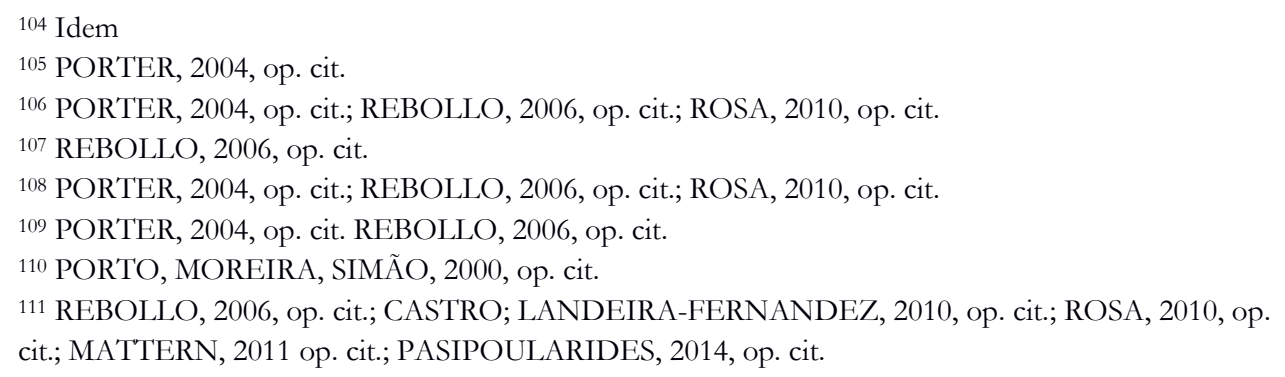


Platão (428 a 348 a.C.) era um dos filósofos que Galeno mais respeitava, tendo fundado em Atenas, em 368 a.C., a Academia, sua escola. A afinidade entre Platão e Galeno apareceu por creditarem ao cérebro a sede do pensamento e da sensibilidade, sendo, ambos, encefalocentris$\operatorname{tas}^{112}$. De Platão, Galeno aproximou-se também em aspectos tais como a teoria platônica das três formas de vida, a psíquica, a animal e a vegetativa ${ }^{113}$. Para Platão havia três espécies espirituais no corpo humano, sendo apenas uma delas imortal, a qual se localizava na cabeça e tinha domínio sobre o restante do corpo (forma de vida psíquica); a outra espécie, irracional, situavase no tórax e era a sede de sentimentos como medo, raiva, esperança (forma de vida animal); a terceira, era a espécie espiritual, sem razão, opinião ou inteligência, a sede das paixões, desejos e inconsciência (a forma de vida vegetativa) ${ }^{114}$. Esta teoria não foi totalmente original, uma vez que Demócritos (contemporâneo de Platão) havia feito a distinção entre o espírito racional e irracional e algumas características importantes desta visão tripartida derivaram da especulação de Pitágoras ${ }^{115}$.

Galeno foi fortemente influenciado por Aristóteles (384 a 322 a.C.), filósofo nascido em Estagira e que realizou ilustrações do corpo humano, as quais são as primeiras figuras anatômicas que se tem conhecimento. Ocorre que não executou dissecações em humanos, acompanhando desta forma a tradição grega da anatomia e fisiologia ${ }^{116}$. Acreditava na existência de uma alma vegetativa responsável pela nutrição e pela reprodução, pertencente às plantas e aos animais; uma alma sensitiva e motora, nos animais; e uma alma racional, consciente e intelectual, apenas nos homens ${ }^{117}$.

Aristóteles interessou-se por hábitos e doenças da vida animal criando a anatomia comparada e, ao pensar por analogia, suas conclusões se estenderam a circunstâncias da vida animal118. Igualmente a Galeno, buscava a natureza para formulação de suas teorias e, partindo de observações pessoais, estabelecia princípios ou leis naturais ${ }^{119}$. Ocorre que a influência de Aristóteles em Galeno deu-se especialmente em sua atenção à taxonomia, ciência que denomina, descreve e classifica os organismos em grupos, de acordo com suas semelhanças e diferenças.

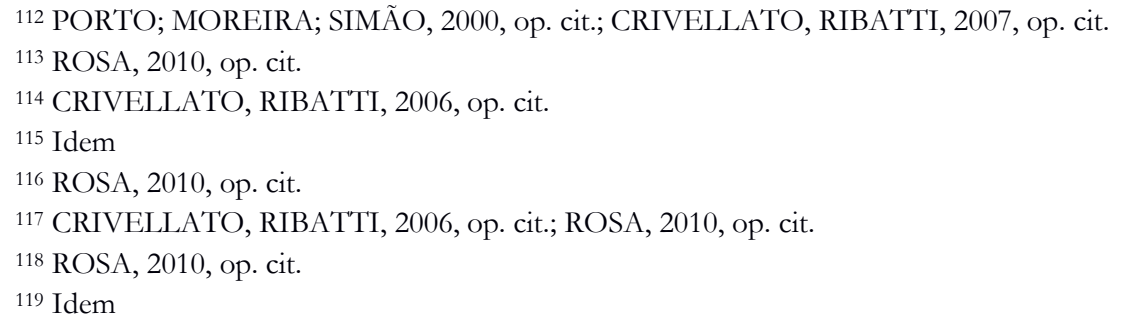


Entretanto, diferentemente de Galeno, Aristóteles acreditava que o coração ocupava a mais alta hierarquia no corpo humano, sendo o centro da razão, dos princípios da vida, da geração de calor do corpo, de sangue e a origem das veias ${ }^{120}$. Ele quem forneceu definitiva autoridade a teoria cardiocêntrica ${ }^{121}$.

Herófilo e Erasístrato, assim como Galeno, foram das novas tradições médicas de Alexandria e Pérgamo, sendo, ambos, também considerados os mais importantes representantes da escola lógica ou dogmática, formulando explicações lógicas e racionais para as causas da saúde e da doença ${ }^{122}$. As primeiras dissecações foram associadas à Herófilo, que parece ter dissecado cadáveres humanos em público, e a seu contemporâneo Erasístrato, que fez experimentos com animais vivos e talvez seres humanos ${ }^{123}$. Posteriormente, Galeno e seus contemporâneos realizaram dissecações e vivissecções em animais.

Herófilo (335 a 280 a.C.), nascido na Calcedônia (Ásia Menor), é considerado o fundador da Anatomia. Foi aluno de Praxágoras e o primeiro a examinar e descrever a estrutura do sistema nervoso, diferenciando-o do sistema cardiovascular, a diferenciar os nervos sensoriais dos motores, o cérebro do cerebelo, a medir a pulsação do sangue pelo corpo ${ }^{124}$, a confirmar o achado de Alcmaeon de que as artérias têm as paredes mais espessas do que as veias ${ }^{125}$. Segundo Galeno, Herófilo descobriu sete pares de nervos cranianos ${ }^{126}$. Seus escritos foram perdidos em um dos incêndios na biblioteca de Alexandria, em 48 a.C., porém, os mesmos tornaram-se conhecidos devido ao testemunho de Galeno, que os teria manuseado ${ }^{127}$.

Erasístrato (304-250 a.C.), nascido em Chio (Grécia), foi essencial à fisiologia, embora tenha se dedicado igualmente à anatomia, prosseguindo os estudos de Herófilo e também de Aristóteles em anatomia comparada. Avançou em relação às descobertas referentes à diferenciação entre os nervos sensitivos e motores e sobre o cérebro, mostrando a comunicação entre os ventrículos encefálicos, tal como entre o terceiro e o quarto ventrículos ${ }^{128}$. Comparou as circunvoluções do cérebro humano com o de outros animais e observou que as complexidades das formações anatômicas, em especial o córtex, relacionavam-se diretamente com a inteligência ${ }^{129}$.

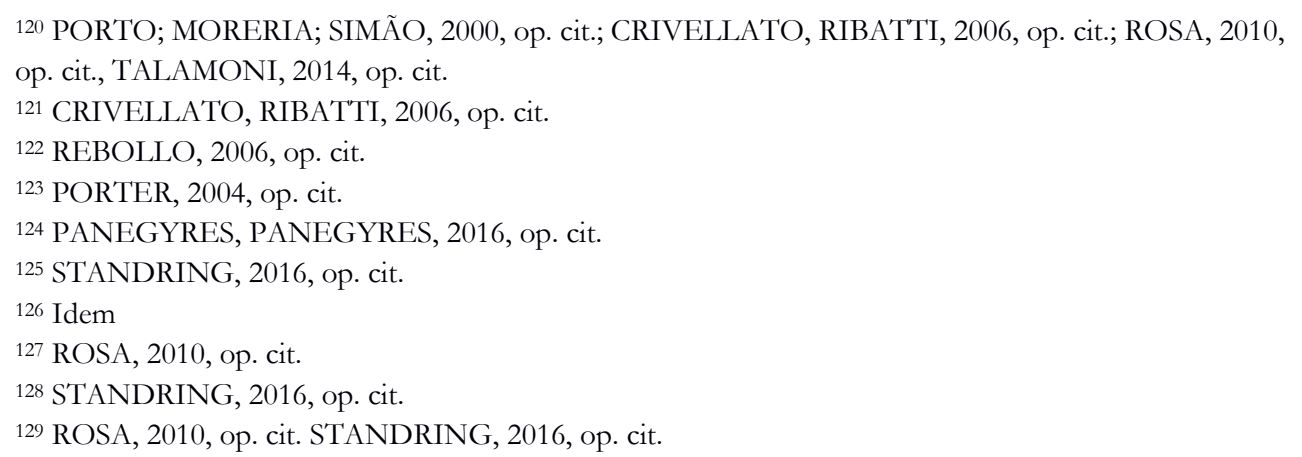


Descreveu as válvulas cardíacas e apontou que o coração assemelhava-se a uma bomba muscu$\operatorname{lar}^{130}$. Iniciou a investigação anatômica em condições patológicas, evidenciando alterações produzidas nos órgãos pelas doenças, e refutou explicações sobrenaturais para os fenômenos biológicos $^{131}$.

O espírito animal foi também descrito por Erasístrato na denominada teoria da nutrição, na qual as veias do fígado continham um espírito natural que alimentava o corpo, enquanto as artérias carreavam um espírito vital até os pulmões (pensava-se que as artérias continham ar, já que pareciam vazios durante a dissecação de corpos humanos) ${ }^{132}$. O espírito vital era conduzido ao coração e, por meio de veias, alcançava o corpo; o espírito vital alcançava o cérebro pelas artérias carótidas, nas quais ele se tornava espírito animal ${ }^{133}$. Erasístrato compreendia que esses espíritos estavam situados nas cavidades do cérebro enviando comandos motores ao corpo pelo trânsito descendente à medula espinal e, por conseguinte, permitia-se a contração muscular ${ }^{134}$.

A anatomia, com Herófilo, e a fisiologia, com Erasístrato, alcançaram importantes avanços através do uso sistemático da dissecação, a qual estava desvendando um novo mundo, o interior do corpo humano e de seus órgãos, já que o mapeamento aprimorado das estruturas antecipa-se a uma compreensão correta das funções. Entretanto, suas descobertas científicas não teriam prosseguimento, uma vez que a medicina, na época, deveria limitar-se a cura dos pacientes e era adjacente ao ressurgimento de uma tendência de considerar a biologia irrelevante ${ }^{135}$.

\section{Considerações Finais}

Galeno revelou e descreveu diversas estruturas e sistemas do corpo humano, bem como aprimorou a explicação de alguns conhecimentos relatados por anatomistas e fisiologistas anteriores a ele. Suas observações práticas foram realizadas a partir de vivissecções e dissecações em animais, já que em humanos eram proibidas, e, por analogia, ele compreendia o organismo humano.

Os entendimentos disseminados por Galeno remetem a filósofos entre os quais se destaca Hipócrates, tendo sido o principal glosador das ideias hipocráticas. Platão, Aristóteles, Herófilo e Erasístrato tiveram também notória importância às reflexões e conclusões galênicas.

\footnotetext{
130 STANDRING, 2016, op. cit.

131 ROSA, 2010, op. cit.

132 BARBARA, CLARAC, 2011, op. cit.; STANDRING, 2016, op. cit.

133 BARBARA, CLARAC, 2011, op. cit.

${ }^{134} \mathrm{Idem}$

135 ROSA, 2010, op. cit.
} 
Galeno extraiu e modificou o conhecimento de acordo com suas vivências e produziu uma síntese coerente da anatomia e da fisiologia tendo como cerne a filosofia.

Há que se destacar sua ampla experiência no atendimento de numerosos e diferentes casos de pacientes, aos quais ele tinha como premissa a ética, a ideia de amizade, sensibilidade e percepção cuidadosa de seus sinais e sintomas. Os ensinamentos de Galeno a respeito da saúde e da doença eram baseados, respectivamente, no equilíbrio ou desequilíbrio dos humores do organismo e na relação do corpo com a natureza. A intervenção médica, para Galeno, deveria ocorrer somente quando a natureza não se mostrasse eficaz.

Por estabelecer comparações entre espécies distintas, foi refutado por alguns estudiosos, mas somente no período do Renascimento, tendo permanecido como autoridade na área médica por cerca de 15 séculos. Seus erros, em decorrência do estudo prático em animais, foram altamente relevantes à evolução da área de saúde, impulsionando a reflexão acerca de seus equívocos e contribuindo para desvendar a correta anatomia e funcionamento do corpo humano.

Sua personalidade baseada em elevados princípios morais e espírito reflexivo e argumentativo, aliada a seu extenso conhecimento prático e teórico, possibilitou-o escrever diversos tratados sobre saúde e doença, relevantes para a ciência de sua época e para pesquisas posteriores, aos quais se adicionava a análise cuidadosa e sensível do tratamento com o paciente. 